\title{
A SYSTEMS ECOLOGY VIEW ON SUSTAINABLE WASTEWATER TREATMENT
}

\author{
Erik Grönlund \\ Inga Carlman \\ Echotechnology and Sustainable Building Engineering, \\ Mid Sweden University, Östersund, Sweden
}

\begin{abstract}
The environmental, economic, and social dimensions of sustainability, were connected in a systems ecology model with focus on wastewater treatment. Life Cycle Assessment and similar approaches are the most common systems analysis models in the wastewater treatment context. These models are beneficial, but are not the only possible approach to systems analysis. The model in this paper showed that the social and economic dimensions were inseparable intertwined, and both of them dependent on the environmental dimension for ecosystem services in the form of natural resources and regenerating capacity. The holistic view, as applied by a systems ecology approach, put focus on how sustainable wastewater treatment are limited to deliver something that can be assimilated by the environmental systems, and in the best applications, produce something that is again useful to the society.
\end{abstract}

KEYWORDS: sewage, sustainable development

\section{INTRODUCTION}

Sustainability is most often defined in terms of three dimensions-environmental, economic and social-and underlining intergenerational equity as expressed by the World Commission on Environment and Development [1] as: "development that meets the needs of the present generation without compromising the ability of future generations to meet their own needs". The sustainability concept and how these three dimensions relate to each other has been much questioned and contested by academics. One wing, mostly social scientists refers to the "three pillars" of sustainability or the "triple-bottom-line" (e.g. [2]). Goodland [3] depicted the three sustainability dimensions with three rings, and sustainable development defined as the area where all three rings overlap. This has also been referred to as weak sustainability. As pointed out by Giddings et al. [4] the problem with this model is that it gives the picture of a separation between environmental, economic, and social aspects, while a probably more true model is that they are interconnected to a large extent (see for example [5]). A good overview of this discussion can be found in Palme [6]. Reasoning from a weak sustainability point of view, denotes that tradeoffs between the three dimensions are permissible. It furthermore implies that discounting and present values are central. Strong sustainability, on the other hand, indicates that tradeoffs between environmental, social and economic dimensions of 
sustainability are restricted or at times simply not allowed, as the focus is on intergenerational justice $[7,8]$.

Mankind's ecological dilemma, strongly underlines our society's ultimate dependence on nature and natural resources. This was also the basis for the world community's decisions in Rio and agenda 21 in 1992 and the following summits. When dealing with sustainability issues, one has to understand that social systems, just like environmental systems, are complex and this call for a systems approach, with focus on holism.

Systems analysis of wastewater treatment has been performed by several authors, e.g. [9-14]. Their approaches took a starting point in Life Cycle Assessment thinking, and produced interesting results. Life Cycle Assessment thinking are, however, not the only possible approach to systems analysis. This paper suggests a systems approach based on systems ecology, covering several of the important aspects identifiable in the context of sustainability and wastewater treatment.

\section{A SYSTEMS SUSTAINABILITY MODEL}

A systems sustainability model was developed based on systems ecology as an alternative to other systems analysis approaches, e.g. life cycle assessment. The model is summarized in Figure 1, where wastewater treatment is placed as an interface between the society and the environment.

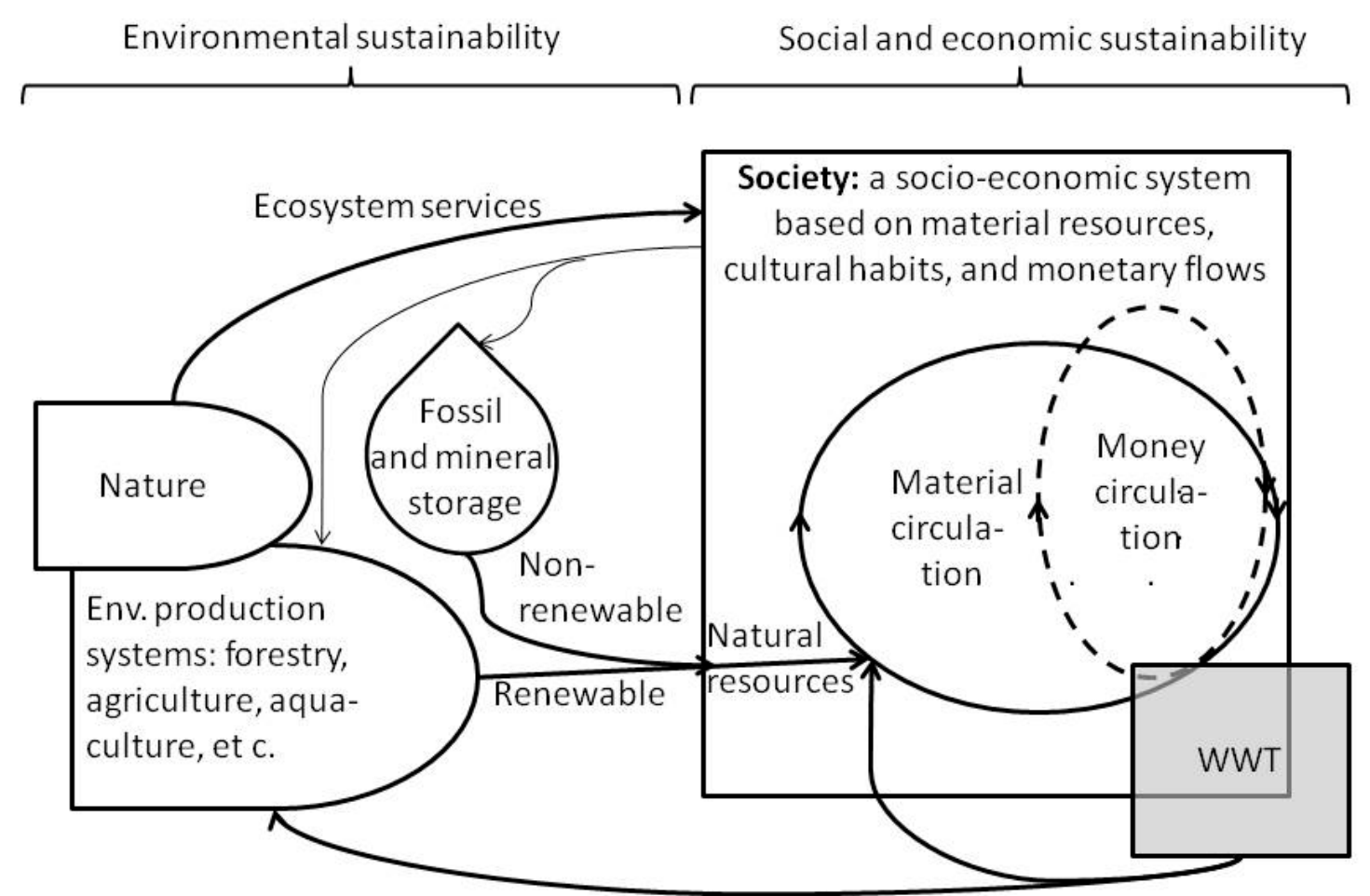

Figure 1. A systems model with relevance to environmental, economic, and social sustainability. $W W T=$ wastewater treatment. 
To the left in the picture are the productive systems of the environment. Here we find lakes and oceans, rivers, wetlands, forests, agricultural land, etc., that provides the human population on earth with natural resources. The natural systems which, even if untouched by human activities, provide us with ecosystem services as biodiversity, the hydrological cycle, scenery and so on [15]. To the left we also have the geological storage of fossil fuels and minerals, which is produced by historical biological and geological processes, and now used by the human population as non-renewable natural resources.

To the right in the picture, in the larger square, is the society. Human settlements form socioeconomic systems based on natural resources, cultural habits, and almost all of them characterized also by monetary flows. Human settlements are also characterized by energy use (not shown in figure 1) and a circulation of materials such as wood, fibers, steel and other metals, plastics, rubber, cotton etc. Some of the used materials go back to the environment as solid waste, gaseous waste, and liquid waste.

In the lower part of the picture the flow of liquid waste is depicted leaving settlements through the wastewater treatment system (WWT). The material from the wastewater treatment system is feed back to lakes, rivers or oceans, or as sludge or irrigation to terrestrial systems as agriculture land or forests. The lakes, rivers, etc., can either manage the discharge or they cannot. In the first case they are able to assimilate discharges without major changes in their functions. An example were they cannot manage the change is when an oligothrophic lake is eutrophicated to a higher nutrient status with algal blooms and oxygen deficiency problems.

A special case is when sludge is delivered to a solid waste dump. In the long run solid waste facilities will not remain as storages. They will rather function as forests or meadows with exchange of nutrients and other substances with the surrounding. In an intermediate time perspective, Günther [16] described a common situation when a solid waste dump is connected to a wastewater treatment plant via collected leachate, and from which sludge is delivered back to the solid waste dump. Every time the leachate reaches the wastewater treatment plant at least $10 \%$ is lost to the recipient, and up to $90 \%$ captured in the sludge and then transported back to the solid waste dump. After many laps of this type almost all the phosphorous has reached the recipient. Günther [16] called these systems HEAP systems (Hampered Effluent Accumulation Process) only delaying phosphorous on its way to the recipient.

The thinner arrows in Figure 1 indicate the small stream of human work, machinery and planning from society to the environmental systems in forestry, agriculture, aquaculture, etc., as compared to the larger natural resource flow.

The WWT square in the picture is placed partly outside the society square. This is because the wastewater treatment facilities can be viewed as an interface or a so called ecotone between the society and the environmental systems as often described in Ecological engineering $[17,18]$. The interface can be a constructed wetland, different types of aquatic ponds, or wastewater irrigation of agricultural or forest land. Even activated sludge or compost can be considered to be in the interface between society and the environmental systems.

\section{THE SYSTEMS SUSTAINABILITY MODEL IN RELATION TO THE THREE SUSTAINABILITY DIMENSIONS}


In the following each dimension of sustainability will be examined in relation to the model in Figure 1.

\subsection{Environmental sustainability}

The environmental sustainability dimension fits well into the model of Figure 1. Environmental sustainability is reflected by the fact that societies depend on natural resources and other ecosystem services as for example Nature as a provider of esthetic services (Figure 1). The systems conditions or socio-ecological principles coined by Azar et al. and Holmberg et al. $[19,20]$ gives a good view of the environmental sustainability dimension. The scope of the systems conditions can be local, regional, or global, and are stated as follows:

1. no systematic increase of concentrations of substances extracted from the earth's crust;

2. no systematic increase of concentrations of substances produced by society;

3. no systematic degradation of the physical conditions for the long-term production capacity in the ecosphere or the diversity of the biosphere

Based on these conditions almost all of our environmental problems can be scrutinized. Below are examples of how the environmental problems of greenhouse gas emissions, eutrophication, acidification, toxic substances, and biodiversity relate to the conditions:

- Greenhouse gas emissions violate condition 1 with a systematic increase of fossil carbon dioxide. Other important greenhouse gases produced by different wastewater treatment processes are methane in anaerobic treatment and nitrous oxide from denitrification processes, and these violates condition 2. Furthermore CFCs and ozone can escape from wastewater treatment plants at accidents. The contribution to greenhouse gas emissions from large scale deforestation of rainforest violates condition 3.

- Eutrophication substances as phosphorus fertilizer violate condition 1, whether or not they have passed wastewater treatment. Nitrogen fertilizer captured from gaseous nitrogen violates condition 2. The high electricity use for the conversion of atmospheric nitrogen gas to nitrogen fertilizer also violates condition 1 if the electricity is produced from coal, oil, or fossil natural gas.

- Acidification: the sulfuric acid originates from oil or coal and violates condition 1 , the nitric acid originates from conversion of nitrogen gas in combustion engines, and violates condition 2. The recently recognized problem of ocean acidification is caused by fossil fuels producing fossil carbon dioxide.

- Toxic substances: the increase stems either from extraction of mercury, lead, cadmium and other heavy metals from the earth's crust violating condition 1, or from society's production of e.g. DDT, PCB, dioxins, or other problematic organic compounds violating condition 2. In wastewater treatment plants organic medical residues is currently rising as a problem.

- Biodiversity: the major part of the biodiversity loss is caused by violation of condition 3 where mainly rainforest areas are systematically decreased. The biodiversity loss caused by changed management methods in the landscape, as is the case in agriculture and forestry is one of the few aspects which is not captured by the conditions.

Environmental sustainability is sometimes also labeled ecological sustainability. An important aspect of ecology is that it is almost always place dependent. This makes it impossible to give general answers to what is sustainable or not. If e.g. groundwater in a region is scarce and the withdrawal is larger than what is regenerated by the hydrological cycle, a low value of a water use indicator can be non-sustainable, while a much higher indicator valued in a groundwater 
rich region is sustainable. The same reasoning is valid for discharges of nutrients as phosphorus and nitrogen. If the capacity of the recipient, local or regional, to incorporate a higher nutrient load without disturbance is high enough decides if it is environment sustainable or not. In principle the same reasoning is also valid for energy use, an indicator often used for comparison to different wastewater treatment methods. If the energy is produced in such a way that the emissions are incorporated to the environment without disturbance it is sustainable, otherwise it is not. The properties of the regional soil and bedrock together with the predominant wind directions decides e.g. what level of acidification discharges from coal or oil burning can be considered sustainable. One must note, however, that carbon dioxide discharges have a global context in this example.

\subsection{Economic sustainability}

Regarding wastewater economic sustainability it is often assessed by the economic costs for the treatment, and this is often appropriate. Economy can, however, be viewed from a larger, and older, perspective, which is how people make their living This is not necessary only measured by monetary flows. In anthropology it is discussed how different tribes make their living, implying how their local economy is composed regarding providing food, material for building houses, fibers and hides for clothes, etc. Within the science of ecology the term "the economy of nature" is sometimes used [21], meaning how different populations or communities (several species living together) make their living regarding food and nutrients. In most modern societies, though, the major part of people's living is mirrored by monetary flows. The point made here is that from a sustainability point of view, economy is not equal to monetary assessment, even though money is often a good estimator of the economy.

Balkema et al. [10] states that "Economic sustainability implies paying for itself, with costs not exceeding benefits." From the above reasoning this is a good rule of thumb. However, as seen in figure 1, the monetary flow is just a subsystem supporting the wanted outcome of a long-term sustained society. This means that some subsectors of the society can have higher costs as long as the system as a whole is sustained. Food and water supply are such examples, but wastewater treatment can also be argued to have this position, since inappropriate wastewater treatment threatens the long-term environmental supporting systems to society.

Balkema et al. [10] also indicate that economy is larger than just the monetary flows: Economic sustainability should mainly “...focusing on increasing human well-being, through optimal allocation and distribution of scarce resources, to meet and satisfy human needs. This approach should, in principle, include all resources. Also those associated with social and environmental values (e.g. in environmental economics). However, in practice most analyses include only the financial costs and benefits." It can be added that ecological economics is the branch including a systems perspective in the spirit of Figure 1, rather than the branch labeled environmental economics (a comparison of environmental economics and ecological economics can be found in e.g. [22]).

The model in figure 1 set constraints for what can be considered economic sustainability. Just assessing and comparing the economic costs for wastewater treatment is not enough. The economic flows are just estimators of flows in the larger system of society.

\subsection{Social sustainability}

Society needs to be maintained, which is the overarching (anthropocentric) goal in Figure 1. This goal is to a large extent already covered by the environmental and economic 
sustainability dimensions. In this perspective the dimension of social sustainability is a residual aspect. Remaining cultural or social aspects are found here. In wastewater treatment these are often aesthetic questions around the wastewater treatment plant such as smell or fitness of the plant in the landscape. But it can also be related to the work environment within the wastewater treatment plant. Balkema et al [10] chose to call this dimension "sociocultural” and highlight aspects as "...human morality...---...human relations, the need for people to interact, to develop themselves, and to organize their society.”

In the context of Figure 1 social and economic sustainability are fully interconnected and dependent of the resources delivery and regenerating capacity of the environmental system.

\subsection{Trade-offs and balancing}

Balkema et al. [10], as well as others, identify that there is often a trade-off regarding the three dimensions of environmental, economic, and social sustainability. And that sustainability is a balancing act: "The forthcoming risks for the environment and for the economy will have to be balanced.” The message from figure 1 is that we cannot claim that an activity is sustainable if it is a result from a negotiation between contradicting environmental and economic demands [23]. Sometimes we can consider such results as being on the path to sustainability, but we must always consider the probable outcome of a created environmental debt, that needs to be taken care of (or paid for) later, on our path to sustainability [24-27].

Another aspect of the sustainability balancing is the hierarchical level in focus. Many papers regarding wastewater treatment and sustainability focus on details in the wastewater treatment plant. But in the context of the above figure 1, the appropriate level is rather the city or the municipality level.

\section{CONCLUSIONS}

In this paper the three dimensions of sustainability-environmental, economic and social-have been discussed in relation to a systems model based on systems ecology, which underlines the connection between the environmental and socio-economic systems, both of them very complex. The model stresses the fact that the social and economic dimensions of sustainability, to an overwhelming extent, are intertwined and inseparable. These two dimensions are furthermore totally dependent on nature and the environment.

A holistic view, as applied by a systems ecology approach, widens the problematization of wastewater and how it could be treated. Instead of concentrating on the upcoming problem of removing already formed contaminants from the wastewater (end of the pipe and best available technique), its goes beyond that, and put focus on how sustainable wastewater treatment are constrained to deliver something that can be assimilated by the environmental systems, and in the best cases, produce something that is again useful to the society.

\section{ACKNOWLEDGMENTS}

We gratefully acknowledge the financial support of the European Union Regional Development Fund for part of this research. 


\section{REFERENCES}

[1] WCED, 1987. Our common future. World Commission on Environment and Development (WCED), United Nations Environment Programme: Nairobi.

[2] Rogers, P.P.; Jalal, K.F.; Boyd, J.A., 2008. An introduction to sustainable development. Earthscan: London.

[3] Goodland, R., 1995. The concept of environmental sustainability. Annual Review of Ecology and Systematics 26, 1-24.

[4] Giddings, B.; Hopwood, B.; O’Brien, G., 2002. Environment, economy and society: Fitting them together into sustainable development. Sustainable Development 10, 187-196.

[5] Odum, H.T., 1994. Ecological and general systems - an introduction to systems ecology. Univ. Press of Colorado: Niwot, 644 pp.

[6] Palme, U., 2007. The role of indicators in developing sustainable urban water systems. Environmental Systems Analysis, Department of Energy and Environment, Chalmers University of Technology: Göteborg.

[7] Carlman I.,2010. Do not Miss the Forest for all the Trees. Nordic Environmental Law Journal 2010:1, 69-81.

[8] Moffatt I., 2007. Environmental space, material flow analysis and ecologial footprinting. In Handbook of Sustainable Development, Atkinson et.al., Eds. Edward Elgar, UK. [9] Balkema, A.J.; Preisig, H.A.; Otterpohl, R.; Lambert, A.J.; Weijers, S.R., 2001. Developing a model based decision support tool for the identification of sustainable treatment options for domestic wastewater. Wat. Sci. Tech. 43, 265-270.

[10] Balkema, A.J.; Preisig, H.A.; Otterpohl, R.; Lambert, F.J.D., 2002. Indicators for the sustainability assessment of wastewater treatment systems. Urban Water 4, 153-161.

[11] Lundin, M., 2003. Indicators for measuring the sustainability of urban water systems - a life cycle approach. Chalmers University of Technology, Göteborg, Sweden.

[12] Lundin, M.; Molander, S.; Morrison, G.M., 1999. A set of indicators for the assessment of temporal variations in the sustainability of sanitary systems. Wat. Sci. Tech. 39, 235-242.

[13] Lundin, M.; Morrison, G.M., 2002. A life cycle assessment based procedure for development of environmental sustainability indicators for urban water systems. Urban Water 4, 145-152.

[14] Bengtsson, M.; Lundin, M.; Molander, S., 1997. Life cycle assessment of wastewater systems. Case studies of conventional treatment, urine sorting and liquid composting in three swedish municipalities.; 1997:9; Technical environmental planning: Göteborg.

[15] MEA, 2005. Ecosystems and human well-being: Synthesis. Millennium Ecosystem Assessment (MEA), Island Press: Washington, DC, 155pp.

[16] Günther, F., 1998. Phosphorus management and societal structure. Hampered effluent accumulation process (heap) in different areas of the swedish society. Vatten 554, 199-208. [17] Mitsch, W.J.; Jørgensen, S.E., 1989. Ecological engineering: An introduction to ecotechnology. Wiley: New York.

[18] Grönlund, E., 2004. Microalgae at wastewater pond treatment in cold climate - an ecological engineering approach. Doctoral thesis 2004:61, Luleå University of Technology, Luleå, Sweden.

[19] Azar, C.; Holmberg, J.; Lindgren, K., 1996. Socio-ecological indicators for sustainability. Ecological Economics 18, 89-112.

[20] Holmberg, J.; Robèrt, K.-H.; Eriksson, K.-E., 1996. Socio-ecological principles for a sustainable society. In Getting down to earth. Practical applications of ecological economics, Costanza, R.; Olman, S.; Martinez-Alier, J., Eds. International Society of Ecological Economics, Island Press: Washington DC.

[21] Ricklefs, R.E., 2008. The economy of nature. 6th edition ed.; Freeman: New York. 
[22] Grönlund, E.; Hedin, D.; Eriksson, P.-O., 2009. Is emergy best suited for ecological economics, environmental economics, or with an economic context of its own? In Emergy synthesis 5: Theory and applications of the emergy methodology. Proceedings from the fifth biennial emergy research conference, Gainesville, Florida, January, 2008., Brown, M.T., Ed. The Center for Environmental Policy, University of Florida: Gainesville, USA, pp 41-48. [23] Westerlund, S., 2000. Sustainable balancing. In Erkki j. Hollo 1940-28/11-2000 : Juhlajulkaisu, Vihervuori, P.; Kuusiniemi, K.; Salila, J., Eds. Lakimiesliiton kustannus: Helsinki.

[24] Grönlund, E.; Klang, A.; Falk, S.; Hanaeus, J., 2004. Sustainability of wastewater treatment with microalgae in cold climate, evaluated with emergy and socio-ecological principles. Ecological Engineering 22, 155-174.

[25] Robèrt, K.-H., 2000. Tools and concepts for sustainable development, how do they relate to a general framework for sustainable development, and to each other? Journal of Cleaner Production 8, 243-254.

[26] Robèrt, K.-H.; Daly, H.E.; Hawken, P.; Holmberg, J., 1997. A compass for sustainable development. Int. J. Sustain. Dev. World Ecol. 4, 79-92.

[27] Robèrt, K.-H.; Schmidt-Bleek, B.; Aloisi de Larderel, J.; Basile, G.; Jansen, J.L.; Kuehr, R.; Price Thomas, P.; Suzuki, M.; Hawken, P.; Wackernagel, M., 2002. Strategic sustainable development - selection, design and synergies of applied tools. Journal of Cleaner Production $10,197-214$. 